\title{
Choice of Strata Boundaries for Allocation Proportional to Stratum Cluster Totals in Stratified Cluster Sampling
}

\author{
Bhuwaneshwar Kumar Gupt ${ }^{1, *}$, F. Lalthlamuanpuii ${ }^{1}$, Md. Irphan Ahamed ${ }^{2}$ \\ ${ }^{1}$ Department of Statistics, North-Eastern Hill University, Shillong, 793022, India \\ ${ }^{2}$ Department of Mathematics, Umshyrpi College, Shillong, 793004, India
}

Received June 11, 2021; Revised July 30, 2021; Accepted August 22, 2021

\begin{abstract}
Cite This Paper in the following Citation Styles
(a): [1] Bhuwaneshwar Kumar Gupt, F. Lalthlamuanpuii, Md. Irphan Ahamed, "Choice of Strata Boundaries for Allocation Proportional to Stratum Cluster Totals in Stratified Cluster Sampling," Mathematics and Statistics, Vol. 9 , No. 5, pp. 697 - 710, 2021. DOI: 10.13189/ms.2021.090509.
\end{abstract}

(b): Bhuwaneshwar Kumar Gupt, F. Lalthlamuanpuii, Md. Irphan Ahamed (2021). Choice of Strata Boundaries for Allocation Proportional to Stratum Cluster Totals in Stratified Cluster Sampling. Mathematics and Statistics, 9(5), 697 710. DOI: $10.13189 / \mathrm{ms} .2021 .090509$.

Copyright $\bigcirc 2021$ by authors, all rights reserved. Authors agree that this article remains permanently open access under the terms of the Creative Commons Attribution License 4.0 International License

\begin{abstract}
In survey planning, sometimes, there arises situation to use cluster sampling because of nature of spatial relationship between elements of population or physical feature of land over which elements are dispersed or unavailability of reliable list of elements. At the same time, there requires technique and strategy for ensuring precision of the sample in representing the parent population. Although several theoretical cum practical works have been done in cluster sampling, stratified sampling and stratified cluster sampling, so far, the problem of stratified cluster sampling for a study variable based on an auxiliary variable, which is required in practice, has never been approached. For the first time, this paper deals with the problem of optimum stratification of population of clusters in cluster sampling with clusters of equal size of a characteristic $y$ under study based on highly correlated concomitant variable $x$ for allocation proportional to stratum cluster totals under a super population model. Equations giving optimum strata boundaries (OSB) for dividing population, in which sampling unit of the population is a cluster, are obtained by minimising sampling variance of the estimator of population mean. As the equations are implicit in nature, a few methods of finding approximately optimum strata boundaries (AOSB) are deduced from the equations giving OSB. In deriving the equations, mathematical tools of calculus and algebra are used in addition to statistical methods of finding conditional expectation of variance. All the proposed methods of stratification are empirically
\end{abstract}

examined by illustrating in live data, population of villages in Lunglei and Serchhip districts of Mizoram State, India, and found to perform efficiently in stratifying the population. The proposed methods may provide practically feasible solution in planning socio-economic survey.

Keywords Allocation, Gamma Probability Density Function, Cluster Size, Optimum Strata Boundaries, Stratified Cluster Sampling, Stratification Variable

\section{Introduction}

In stratified sampling, a heterogeneous population is divided into a number of groups called strata which are within strata homogeneous and sample is selected from strata using suitable sample selection method; the method is used for administrative convenience and enhancing the precision of representation of the sample for the parent population. On the other hand, when the availability of reliable list of elements (units) of population is difficult or the elements are spatially dispersed in such a way that there requires lots of energy, time and cost while surveying the elements selected by simple random sampling, cluster sampling or area sampling is employed by grouping the contiguous elements or elements, which can be conveniently surveyed together without much extra effort, into clusters; then, the clusters are taken as 
sampling units of population while selecting sample from the population. The strategy used in cluster sampling for enhancing its precision is to make the population within cluster as heterogeneous as possible and increase inter cluster homogeneity as much as possible. Formation of cluster primarily depends on the spatial relationships between elements in terms of geographical contiguity, good connectivity and convenience in surveying together, less energy, resource and time while surveying the elements within cluster, in addition to scheming for increasing intra-cluster heterogeneity and inter-cluster homogeneity. When the clusters are considered as sampling units of population and then stratified by methods of stratified sampling, the inter cluster homogeneity is increased within strata of clusters which in turn serves the purpose of scheming in cluster sampling for enhancing the precision of representation of sample for the parent population.

In stratified sampling, ever since Dalenius [1] introduced the problem of finding optimum strata boundaries (OBS) based on Tschuprow [2] and Neyman [3] optimum allocation (TNOA) for enhancing homogeneity within strata, the vastness of research in the area has been increasing as a number of researchers, inter alia, Dalenius and Gurney [4], Mahalanobis [5], Hansen et al. [6], Dalenius and Hodges [7,8], Ekman [9], etc., embarked on the work who initially used study variable as stratification variable. As the use of study variable as stratification variable is unrealistic, many workers mostly in the later years extended the work of finding OSB and AOSB by using an auxiliary variable which is highly correlated with the study variable. Dalenius [10], Taga [11], Singh and Sukhatme [12], Singh [13-16], Singh and Prakash [17], Yadava and Singh [18], etc., to mention a few among many, worked on the problem of finding OSB and AOSB based on auxiliary variable for various allocations under different sampling designs. The problem of optimum stratification was again considered from the perspective of more than one study variable by, inter alia, Ghosh [19], Gupta and Seth [20], Rizvi et al. [21,22] etc., whereas Danish and Rizvi [23] approached the problem from the perspective of two auxiliary variables having one study variable.

It is pertinent to mention that in the direction of development of allocation of sample size to strata in stratified sampling, ever since Tschuprow [2] and Neyman [3] proposed TNOA based on study variable, it is Hanurav [24] and Rao [25] who introduced using auxiliary variable under a superpopulation model considered by them. Gupt and Rao [26] obtained allocation of sample size to strata for probability proportional to size under the superpopulation model. Gupt $[27,28]$ modified the aforesaid superpopulation model into a more general form and hence obtained a few generalised model-based allocations; Gupt and Ahamed [29,30] obtained a few methods of stratification for some of the generalised model-based allocations under simple random sampling with and without replacement (SRSWR and SRSWOR) in the form of equations giving OSB and solutions to the equations giving AOSB. Gupt et al. [31] also obtained methods of stratification giving OSB and AOSB for auxiliary variable optimum allocation (AOSB) obtained by Hanurav [24].

In the area of stratified cluster sampling, Mehta and Mandowara [32] considered problem of finding OSB and AOSB in stratifying population based on study variable for TNOA, proportional and equal allocation under SRSWOR design.

For the first time, we have introduced in this paper the problem of optimum stratification for a characteristic under study $y$ based on a highly correlated auxiliary variable $x$ in stratified cluster sampling with clusters of equal size under the following superpopulation model which is a modified form of the model used by Hanurav [24] and Rao [25].

$$
\begin{aligned}
& \text { (i) } \xi\left(y_{i} \mid x_{i}\right)=\alpha+\beta x_{i} \\
& \text { (ii) } \mathrm{V}\left(y_{i} \mid x_{i}\right)=\sigma^{2} x_{i} \\
& \text { (iii) } \varsigma\left(y_{i}, y_{j} \mid x_{i}, x_{j}\right)=0
\end{aligned}
$$

where $\alpha, \beta$ and $\sigma^{2}$ are the superpopulation parameters with $\sigma^{2}>0$ and the scripts $\xi, V$ and $\varsigma$ denote conditional expectation, variance and covariance given $x$ 's respectively.

Here in this paper, the crux of the work is to simultaneously address the inevitable conditions of spatial relationship of elements leading to the use of cluster sampling and scheming for increasing inter-cluster homogeneity and intra-cluster heterogeneity to increase precision of the sampling.

We use information on the auxiliary variable $x$ which is highly correlated with study variable $y$ to stratify population whose units are clusters whereas clusters are formed by grouping the elements in the way discussed above elaborately; the allocation and sample selection procedure used in this work are allocation proportional to stratum total and SRSWR, which will hold true for SRSWOR too when finite population correction is neglected.

The paper has six sections. Section 2 deals with obtaining conditional expectation of population variance between cluster means. In section 3, the derivation of equations giving OSB is presented. In section 4 , a few methods of finding AOSB are presented. In Section 5, empirical illustration of all the proposed methods of stratification is carried out in live data and results are discussed. Section 6 gives the conclusion.

\section{Expression for Conditional Expectation of Population Variance between Clusters Means}

Considering a population consists of $N$ clusters of $M$ 
elements each and a sample of $\mathrm{n}$ clusters is to be selected from $\mathrm{N}$ clusters by SRSWR. Let $Y_{i j}$ be the value of characteristic under study for the $j^{\text {th }}$ element in the $i^{\text {th }}$ cluster, $j=1,2, \ldots, M ; i=1,2, \ldots, N$. Then, mean square between the cluster means, $\sigma_{b y}^{2}=\frac{1}{N} \sum_{i=1}^{N}\left(\bar{Y}_{i}-\overline{\bar{Y}}\right)^{2}$, where $\bar{Y}_{i}$ and $\overline{\bar{Y}}$ are the means of the $i^{\text {th }}$ cluster and cluster means. $\sigma_{b y}^{2}$ can again be expressed as $\sigma_{b y}^{2}=$ $\frac{1}{M^{2}} \sigma_{T}^{2}$, where $\sigma_{T}^{2}=\frac{1}{N} \sum_{i=1}^{N}\left(Y_{i}-\bar{Y}\right)^{2}$ is the mean square of cluster totals and $\bar{Y}$ is the mean of cluster totals

$$
\begin{aligned}
& \Rightarrow \sigma_{b y}^{2}=\frac{1}{N M^{2}} \sum_{i=1}^{N}\left(\sum_{j=1}^{M} Y_{i j}\right)^{2}-\frac{1}{M^{2}}\left(\frac{\sum_{i=1}^{N} Y_{i}}{N}\right)^{2} \\
& =\frac{1}{N M^{2}} \sum_{i=1}^{N} \sum_{j=1}^{M} Y_{i j}^{2}+\frac{1}{N M^{2}} \sum_{i=1}^{N} \sum_{J=1}^{M} \sum_{\substack{j^{\prime}=1 \\
j \neq j^{\prime}}}^{M} Y_{i j} Y_{i j^{\prime}} \\
& -\frac{1}{N^{2} M^{2}}\left(\sum_{i=1}^{N} Y_{i}^{2}+\sum_{i=1}^{N} \sum_{\substack{i^{\prime}=1 \\
i \neq i^{\prime}}}^{N} Y_{i} Y_{i^{\prime}}\right) \\
& =\frac{1}{N M^{2}} \sum_{i=1}^{N} \sum_{j=1}^{M} Y_{i j}^{2}+\frac{1}{N M^{2}} \sum_{i=1}^{N} \sum_{J=1}^{M} \sum_{\substack{j^{\prime}=1 \\
j \neq j^{\prime}}}^{M} Y_{i j} Y_{i j^{\prime}} \\
& -\frac{1}{N^{2} M^{2}} \sum_{i=1}^{N}\left\{\sum_{j=1}^{M} Y_{i j}^{2}+\sum_{j=1}^{M} \sum_{\substack{j^{\prime}=1 \\
j \neq j^{\prime}}}^{M} Y_{i j} Y_{i j^{\prime}}\right\} \\
& -\frac{1}{N^{2} M^{2}} \sum_{i=1}^{N} \sum_{\substack{i^{\prime}=1 \\
i \neq i^{\prime}}}^{N}\left(\sum_{j=1}^{M} Y_{i j}\right)\left(\sum_{k=1}^{M} Y_{i k}\right) \\
& \Rightarrow \sigma_{b y}^{2}=\frac{1}{N M^{2}}\left(1-\frac{1}{N}\right) \\
& \left\{\sum_{i=1}^{N} \sum_{j=1}^{M} Y_{i j}^{2}+\sum_{i=1}^{N} \sum_{j=1}^{M} \sum_{\substack{j^{\prime}=1 \\
j \neq j^{\prime}}}^{M} Y_{i j} Y_{i j^{\prime}}\right\} \\
& -\frac{1}{N^{2} M^{2}} \sum_{i=1}^{N} \sum_{\substack{i^{\prime}=1 \\
i \neq i^{\prime}}}^{N} \sum_{j=1}^{M} \sum_{k=1}^{M} Y_{i j} Y_{i^{\prime} k}
\end{aligned}
$$

Taking conditional expectation of (2) given $x$ 's

$$
\begin{gathered}
\xi\left(\sigma_{b y}^{2} \mid x\right)=\frac{1}{N M^{2}}\left(1-\frac{1}{N}\right) \\
\left\{\sum_{i=1}^{N} \sum_{j=1}^{M} \mathrm{~V}\left(Y_{i j} \mid X_{i j}\right)+\sum_{i=1}^{N} \sum_{j=1}^{M}\left(\xi\left(Y_{i j} \mid X_{i j}\right)\right)^{2}\right\} \\
+\frac{1}{N M^{2}}\left(1-\frac{1}{N}\right) \sum_{i=1}^{N} \sum_{j=1}^{M} \sum_{\substack{j^{\prime}=1 \\
j \neq j^{\prime}}}^{M}\left\{\xi\left(Y_{i j} \mid X_{i j}\right) \xi\left(Y_{i j^{\prime}} \mid X_{i j^{\prime}}\right)+\right. \\
\left.\varsigma\left(Y_{i j}, Y_{i j^{\prime}} \mid X_{i j}, X_{i j^{\prime}}\right)\right\}-\frac{1}{N^{2} M^{2}} \\
\sum_{i=1}^{N} \sum_{\substack{i^{\prime}=1 \\
i \neq i^{\prime}}}^{N} \sum_{j=1}^{M} \sum_{k=1}^{M}\left\{\xi\left(Y_{i j} \mid X_{i j}\right) \xi\left(Y_{i^{\prime} k} \mid X_{i^{\prime} k}\right)+\right. \\
\left.\varsigma\left(Y_{i j}, Y_{i^{\prime} k} \mid X_{i j}, X_{i^{\prime} k}\right)\right\}
\end{gathered}
$$

Using (1) in (3), we get

$$
\begin{gathered}
\xi\left(\sigma_{b y}^{2} \mid x\right)=\frac{1}{N M^{2}}\left(1-\frac{1}{N}\right) \\
\left\{\sum_{i=1}^{N} \sum_{j=1}^{M} \sigma^{2} X_{i j}+\sum_{i=1}^{N} \sum_{j=1}^{M}\left(\alpha+\beta X_{i j}\right)^{2}\right\} \\
+\frac{1}{N M^{2}}\left(1-\frac{1}{N}\right) \sum_{i=1}^{N} \sum_{j=1}^{M} \sum_{\substack{j^{\prime}=1 \\
j \neq j^{\prime}}}^{M}\left(\alpha+\beta X_{i j}\right)\left(\alpha+\beta X_{i j^{\prime}}\right)
\end{gathered}
$$

$$
-\frac{1}{N^{2} M^{2}} \sum_{i=1}^{N} \sum_{\substack{i^{\prime}=1 \\ i \neq i^{\prime}}}^{N} \sum_{j=1}^{M} \sum_{k=1}^{M}\left(\alpha+\beta X_{i j}\right)\left(\alpha+\beta X_{i^{\prime} k}\right)
$$

On simplification, we get

$$
\xi\left(\sigma_{b y}^{2} \mid x\right)=\beta^{2} \sigma_{b x}^{2}+\frac{\sigma^{2}(N-1)}{N^{2} M^{2}} \sum_{i=1}^{N} \sum_{j=1}^{M} X_{i j},
$$

where $\sigma_{b x}^{2}=\frac{1}{N} \sum_{i=1}^{N}\left(\bar{X}_{i}-\overline{\bar{X}}\right)^{2}$

\section{Derivation of Methods of Finding Optimum Strata Boundaries}

The conditional expectation of $\sigma_{b y}^{2}$ given $x$ in (4) can be expressed as

$$
\xi\left(\sigma_{b y}^{2} \mid x\right)=\frac{\beta^{2}}{M^{2}} \sigma_{x T}^{2}+\frac{\sigma^{2}(N-1)}{N M^{2}} \mu_{x T},
$$

where $\sigma_{x T}^{2}=\frac{1}{N} \sum_{i=1}^{N}\left(X_{i}-\bar{X}\right)^{2}$ is the mean square of the cluster totals and $\mu_{x T}$ is the mean of cluster totals of the population for the $x$ variable.

From this step onwards, we consider the notations $y$ and $x$ as the study variable and auxiliary variable respectively for cluster totals as unit of population, then we can rewrite (5) as

$$
\xi\left(\sigma_{b y}^{2} \mid x\right)=\frac{\beta^{2}}{M^{2}} \sigma_{x}^{2}+\frac{\sigma^{2}(N-1)}{N M^{2}} \mu(x)
$$

For stratification purpose, we divide the population of $\mathrm{N}$ units into L number of strata such that $\sum_{h=1}^{L} N_{h}=N$ and a sample of size $n_{h}$ is selected by SRSWR from $h^{\text {th }}$ stratum of size $N_{h}$ such that $\sum_{h}^{L} n_{h}=n$.

Sampling variance of the estimator of the population mean in stratified sampling for the study variable is $\mathrm{V}\left(\bar{y}_{s t}\right)=\sum_{h=1}^{L} \frac{W_{h}^{2} \sigma_{h y}^{2}}{n_{h}}$, where $W_{h}$ is the weight of $h^{t h}$ stratum.

$$
\Rightarrow \xi\left\{V\left(\bar{y}_{s t} \mid \boldsymbol{X}\right)\right\}=\sum_{h=1}^{L} \frac{W_{h}^{2} \xi\left(\sigma_{h y}^{2} \mid \underline{X}_{h}\right)}{n_{h}}
$$

where $\boldsymbol{X}=\left(\underline{X}_{1}, \underline{X_{2}} \ldots, \underline{X}_{N}\right)$

and $\underline{X}_{h}^{\prime}=\left(X_{h 1} X_{h 2} \ldots X_{N_{h}}\right)$.

Since, the allocation proportional to stratum total of the auxiliary variable is considered, we have

$$
\begin{gathered}
n_{h} \propto X_{h} \\
\Rightarrow n_{h}=\frac{n W_{h} \mu_{h}(x)}{\bar{X}}
\end{gathered}
$$

where $\mu_{h}(x)$ is the mean the $h^{\text {th }}$ stratum and $\bar{X}$ is the population mean of the $x$ variable.

From (6), (7) and (8), we get

$$
\begin{aligned}
& n \xi\left\{V\left(\bar{y}_{s t} \mid \boldsymbol{X}\right)\right\}=\bar{X} \sum_{h=1}^{L}\left\{\frac{\beta^{2}}{M^{2}} \frac{W_{h}^{2} \sigma_{h x}^{2}}{W_{h} \mu_{h}(x)}+\frac{\sigma^{2} W_{h}^{2}\left(N_{h}-1\right) \mu_{h}(x)}{N_{h} M^{2} W_{h} \mu_{h}(x)}\right\} \\
& \Rightarrow n \xi\left\{V\left(\bar{y}_{s t} \mid \boldsymbol{X}\right)\right\}=\frac{\bar{X} \beta^{2}}{M^{2}} \sum_{h=1}^{L} \frac{W_{h} \sigma_{h x}^{2}}{\mu_{h}(x)}+\frac{\sigma^{2} \bar{X}(N-L)}{N M^{2}} .
\end{aligned}
$$


If $\mathrm{f}(x)$ is probability density function, we can get

$$
\begin{gathered}
W_{h}=\int_{x_{h-1}}^{x_{h}} f(t) d t \\
W_{h} \mu_{h}(x)=\int_{x_{h-1}}^{x_{h}} t f(t) d t \\
\left\{\sigma_{h x}^{2}+\mu_{h}^{2}(x)\right\} W_{h}=\int_{x_{h-1}}^{x_{h}} t^{2} f(t) d t
\end{gathered}
$$

Minimising $n \xi\left\{V\left(\bar{y}_{s t} \mid \boldsymbol{X}\right)\right\}$ in (9) is equivalent to minimising $\sum_{h=1}^{L} \frac{W_{h} \sigma_{h x}^{2}}{\mu_{h}(x)}$,

Therefore, we take $\frac{\delta}{\delta x_{h}} \sum_{h=1}^{L} \frac{W_{h} \sigma_{h x}^{2}}{\mu_{h}(x)}=0$.

All other terms

except

$\frac{\delta}{\delta x_{h}}\left(\frac{W_{h} \sigma_{h x}^{2}}{\mu_{h}(x)}\right) \& \frac{\delta}{\delta x_{h}}\left(\frac{W_{h+1} \sigma_{(h+1) x}^{2}}{\mu_{h+1}(x)}\right)$ will vanish, therefore, we get

$$
\frac{\delta}{\delta x_{h}}\left(\frac{W_{h} \sigma_{h x}^{2}}{\mu_{h}(x)}\right)+\frac{\delta}{\delta x_{h}}\left(\frac{W_{h+1} \sigma_{(h+1) x}^{2}}{\mu_{h+1}(x)}\right)=0 .
$$

Considering the first term of (11) and using (10)

$$
\begin{gathered}
\frac{\delta}{\delta x_{h}}\left(W_{h} \sigma_{h x}^{2}\right)=\left\{x_{h}-\mu_{h}(x)\right\}^{2} f\left(x_{h}\right), \text { and } \\
\frac{\delta}{\delta x_{h}}\left\{\frac{W_{h} \sigma_{h x}^{2}}{\mu_{h}(x)}\right\}=\frac{\left\{x_{h}-\mu_{h}(x)\right\}\left\{\mu_{h}(x) x_{h}-\mu_{h}^{2}(x)-\sigma_{h x}^{2}\right\}}{\mu_{h}^{2}(x)} f\left(x_{h}\right) .
\end{gathered}
$$

Similarly, we can get the second term of (11) as

$$
\begin{array}{r}
\frac{\delta}{\delta x_{h}}\left\{\frac{W_{h+1} \sigma_{(h+1) x}^{2}}{\mu_{h+1}(x)}\right\}= \\
\frac{\left\{x_{h}-\mu_{h+1}(x)\right\}\left\{\mu_{h}+1(x) x_{h}-\mu_{h+1}^{2}(x)-\sigma_{(h+1) x}^{2}\right\}}{\mu_{h+1}^{2}(x)}\left\{-f\left(x_{h}\right)\right\} .
\end{array}
$$

From (11), (12) and (13), we get

$$
\begin{aligned}
& \frac{\left\{x_{h}-\mu_{h}(x)\right\}\left\{\mu_{h}(x) x_{h}-\mu_{h}^{2}(x)-\sigma_{h x}^{2}\right\}}{\mu_{h}^{2}(x)} \\
= & \frac{\left\{x_{h}-\mu_{h+1}(x)\right\}\left\{\mu_{h}+1(x) x_{h}-\mu_{h+1}^{2}(x)-\sigma_{(h+1) x}^{2}\right\}}{\mu_{h+1}^{2}(x)} .
\end{aligned}
$$

Equations (14) give OSB for the estimation variable $y$ based on auxiliary variable $x$. We call (14) as exact equations.

\section{Derivation of Methods of Finding AOSB Corresponding to the Exact Equations}

\subsection{Approximation Based on Series Expansion}

Since the exact equations (14) are implicit, i.e., equations consist of parameters which are the functions of OSB, it is difficult in solving for OSB in stratifying populations. Therefore, in this section, we carry out derivation for obtaining the solutions of equations (14) which give AOSB. Singh and Sukhatme [12] developed a technique to use Ekman's [33] identity for obtaining series expansion of conditional mean and variance. Gupt and Ahamed [29,30], Gupt et al. [31] used the technique for obtaining series expansion of conditional mean and variance for some functions. Here, in this paper too, the same technique is used for which we assume the existence of continuity and first three partial derivatives of $f(x)$ with respect to $x, \forall x \in\left(x_{h-1}, x_{h+1}\right)$ for all the values of $h$. For expanding, right hand side of equations (14) about the point $x_{h}$,we take $k_{h+1}=x_{h+1}-x_{h}$ and all the derivatives are evaluated at $x_{h}$. Thus series expansion of conditional mean and variance are obtained as follows:

$$
\begin{gathered}
\mu_{(h+1) x}=x_{h}+\frac{k_{h+1}}{2}+\frac{f^{\prime}}{12 f} k_{h+1}^{2}+\frac{f f^{\prime \prime}-f^{\prime^{2}}}{24 f^{2}} k_{h+1}^{3} \\
+\frac{9 f^{\prime \prime \prime} f^{2}-25 f f^{\prime} f^{\prime \prime}+15 f^{\prime 3}}{720 f^{3}} k_{h+1}^{4}+O\left(k_{h+1}^{4}\right) . \\
\sigma_{(h+1) x}^{2}=\frac{k_{h+1}^{2}}{12}+\frac{2 f f^{\prime \prime}-5 f^{\prime 2}}{720 f^{2}} k_{h+1}^{4}+O\left(k_{h+1}^{5}\right)
\end{gathered}
$$

From (15), we get

$$
\begin{gathered}
\frac{x_{h}}{\mu_{(h+1) x}}=x_{h} \mu_{(h+1) x}^{-1} \\
=x_{h} x_{h}^{-1}\left\{1+\frac{k_{h+1}}{2 x_{h}}+\frac{f^{\prime}}{12 f x_{h}} k_{h+1}^{2}+\frac{f f^{\prime \prime}-f^{\prime 2}}{24 f^{2} x_{h}} k_{h+1}^{3}\right. \\
\left.+\frac{9 f^{\prime \prime \prime} f^{2}-25 f f^{\prime} f^{\prime \prime}+15 f^{\prime 3}}{720 f^{3} x_{h}} k_{h+1}^{4}+O\left(k_{h+1}^{5}\right)\right\}^{-1} \\
\Rightarrow \frac{x_{h}}{\mu_{(h+1) x}}=1-\frac{k_{h+1}}{2 x_{h}}+\frac{3 f-f^{\prime} x_{h}}{12 f x_{h}^{2}} k_{h+1}^{2} \\
+\frac{2 f f^{\prime} x_{h}-3 f^{2}-f f^{\prime \prime} x_{h}^{2}+f^{\prime 2} x_{h}^{2}}{24 f^{2} x_{h}^{3}} k_{h+1}^{3} \\
+\frac{\left(\begin{array}{c}
45 f^{3}-25 f f^{\prime 2} x_{h}^{2}-45 f^{2} f^{\prime} x_{h}+30 f^{2} f^{\prime \prime} x_{h}^{2} \\
-9 f^{\prime \prime \prime} f^{2} x_{h}^{3}+25 f f^{\prime} f^{\prime \prime} x_{h}^{3}-15 f^{\prime 3} x_{h}^{3}
\end{array}\right.}{720 f^{3} x_{h}^{4}} k_{h+1}^{4}+O\left(k_{h+1}^{5}\right)
\end{gathered}
$$

Again from (15) and (16), we get

$$
\begin{gathered}
\frac{\sigma_{(h+1) x}^{2}}{\mu_{(h+1) x}^{2}}=\left\{\frac{k_{h+1}^{2}}{12}+\frac{2 f f^{\prime \prime}-5 f^{\prime^{2}}}{720 f^{2}} k_{h+1}^{4}+O\left(k_{h+1}^{5}\right)\right\} \\
\left\{x_{h}+\frac{k_{h+1}}{2}+\frac{f^{\prime}}{12 f} k_{h+1}^{2}+\frac{f f^{\prime \prime}-f^{\prime 2}}{24 f^{2}} k_{h+1}^{3}\right. \\
\left.+\frac{9 f^{\prime \prime \prime} f^{2}-25 f f^{\prime} f^{\prime \prime}+15 f^{\prime 3}}{720 f^{3}} k_{h+1}^{4}+O\left(k_{h+1}^{4}\right)\right\}^{-2} \\
=x_{h}^{-2}\left\{\frac{k_{h+1}^{2}}{12}-\frac{k_{h+1}^{3}}{12 x_{h}}\right. \\
\left.+\frac{9 f-2 f^{\prime} x_{h}}{144 f x_{h}^{2}} k_{h+1}^{4}+\frac{2 f f^{\prime \prime}-5 f^{\prime 2}}{720 f^{2}} k_{h+1}^{4}\right\} \\
+O\left(k_{h+1}^{5}\right)
\end{gathered}
$$




$$
\begin{gathered}
\Rightarrow \frac{\sigma_{(h+1) x}^{2}}{\mu_{(h+1) x}^{2}} \\
=\frac{k_{h+1}^{2}}{12 x_{h}^{2}}-\frac{k_{h+1}^{3}}{12 x_{h}^{3}}+\frac{45 f^{2}-10 f f^{\prime} x_{h}+2 f f^{\prime \prime} x_{h}^{2}-5 f^{\prime 2} x_{h}^{2}}{720 f^{2} x_{h}^{4}} k_{h+1}^{4}+ \\
O\left(k_{h+1}^{5}\right) .
\end{gathered}
$$

Using (15), (17) and (18) in the exact equations (14), we can get as follows:

$$
\begin{aligned}
& \text { Right Hand Side of equations } \\
& =\left(x_{h}-\mu_{(h+1) x}\right)\left(\frac{x_{h}}{\mu_{(h+1) x}}-1-\frac{\sigma_{(h+1) x}^{2}}{\mu_{(h+1) x}^{2}}\right) \\
& =\left\{-\frac{k_{h+1}}{2}-\frac{f^{\prime}}{12 f} k_{h+1}^{2}-\frac{f f^{\prime \prime}-f^{\prime^{2}}}{24 f^{2}} k_{h+1}^{3}\right. \\
& \left.-\frac{9 f^{\prime \prime \prime} f^{2}-25 f f^{\prime} f^{\prime \prime}+15 f^{\prime^{3}}}{720 f^{3}} k_{h+1}^{4}\right\} \\
& {\left[-\frac{k_{h+1}}{2 x_{h}}+\frac{3 f-f^{\prime} x_{h}}{12 f x_{h}^{2}} k_{h+1}^{2}\right.} \\
& +\frac{2 f f^{\prime} x_{h}-3 f^{2}-f f^{\prime \prime} x_{h}^{2}+f^{\prime 2} x_{h}^{2}}{24 f^{2} x_{h}^{3}} k_{h+1}^{3} \\
& +\frac{\left\{\begin{array}{c}
45 f^{3}-25 f f^{\prime^{2}} x_{h}^{2}-45 f^{2} f^{\prime} x_{h}+30 f^{2} f^{\prime \prime} x_{h}^{2} \\
-9 f^{\prime \prime \prime} f^{2} x_{h}^{3}+25 f f^{\prime} f^{\prime \prime} x_{h}^{3}-15 f^{\prime 3} x_{h}^{3}
\end{array}\right\}}{720 f^{3} x_{h}^{4}} k_{h+1}^{4} \\
& -\frac{k_{h+1}^{2}}{12 x_{h}^{2}} \\
& \left.+\frac{k_{h+1}^{3}}{12 x_{h}^{3}}-\frac{45 f^{2}-10 f f^{\prime} x_{h}+2 f f^{\prime \prime} x_{h}^{2}-5 f^{\prime 2} x_{h}^{2}}{720 f^{2} x_{h}^{4}} k_{h+1}^{4}\right] \\
& +O\left(k_{h+1}^{5}\right) \\
& =\frac{k_{h+1}^{2}}{4 x_{h}}+\frac{f^{\prime} x_{h}-2 f+f^{\prime} x_{h}}{24 f x_{h}^{2}} k_{h+1}^{3} \\
& +\frac{\left\{\begin{array}{l}
3 f f^{\prime \prime} x_{h}^{2}-3 f^{\prime 2} x_{h}^{2}-2 f f^{\prime} x_{h}+f^{\prime 2} x_{h}^{2} \\
-6 f f^{\prime} x_{h}+3 f^{2}+3 f f^{\prime \prime} x_{h}^{2}-3 f^{\prime 2} x_{h}^{2}
\end{array}\right\}}{144 f^{2} x_{h}^{3}} k_{h+1}^{4}+O\left(k_{i}^{5}\right) \\
& =\frac{k_{h+1}^{2}}{4 x_{h}}\left\{1+\frac{f^{\prime} x_{h}-f}{f x_{h}} \frac{k_{h+1}}{3}\right. \\
& \left.+\frac{\left(\begin{array}{c}
6 f f^{\prime \prime} x_{h}^{2}-5 f^{\prime 2} x_{h}^{2} \\
-8 f f^{\prime} x_{h}+3 f^{2}
\end{array}\right)}{36 f^{2} x_{h}^{2}} k_{h+1}^{2}\right\} \\
& +O\left(k_{h+1}^{5}\right) \\
& =\frac{k_{h+1}^{2}}{4 x_{h}}\left\{1+\frac{\frac{\delta}{\delta x_{h}}\left(\frac{f}{x_{h}}\right)}{\left(\frac{f}{x_{h}}\right)} \frac{k_{h+1}}{3}+O\left(k_{h+1}^{2}\right)\right\} \text {. }
\end{aligned}
$$

Thus, we can rewrite the right hand side of equations (14) as

$$
\text { RHS }=\frac{k_{h+1}^{2}}{4 x_{h}}\left\{1+\frac{\frac{\delta}{\delta x_{h}}\left(\frac{f\left(x_{h}\right)}{x_{h}}\right)}{\left(\frac{f\left(x_{h}\right)}{x_{h}}\right)} \frac{k_{h+1}}{3}+O\left(k_{h+1}^{2}\right)\right\} .
$$

Similarly, we can obtain the left hand side of equations (14) as

LHS $=\frac{k_{h}^{2}}{4 x_{h}}\left\{1-\frac{\frac{\delta}{\delta x_{h}}\left(\frac{f\left(x_{h}\right)}{x_{h}}\right)}{\left(\frac{f\left(x_{h}\right)}{x_{h}}\right)} \frac{k_{h}}{3}+O\left(k_{h}^{2}\right)\right\}$, where $k_{h}=x_{h}-$

Therefore, equations (14) can be reduced to

$$
\begin{aligned}
& \frac{k_{h}^{2}}{4 x_{h}}\left\{1-\frac{\{g(t)\}^{\prime}}{g(t)} \frac{k_{h}}{3}+O\left(k_{h}^{2}\right)\right\} \\
= & \frac{k_{h+1}^{2}}{4 x_{h}}\left\{1+\frac{\{g(t)\}^{\prime}}{g(t)} \frac{k_{h+1}}{3}+O\left(k_{h+1}^{2}\right)\right\},
\end{aligned}
$$

where $g(t)=\frac{f(t)}{t}$ and writing $t$ in place the variable $x_{h}$.

On raising power $\frac{3}{2}$ on both sides and expanding by binomial theorem,

$$
\begin{aligned}
& k_{h}^{3}\left\{1-\frac{\{g(t)\}^{\prime}}{g(t)} \frac{k_{h}}{2}+O\left(k_{h}^{2}\right)\right\} \\
= & k_{h+1}^{3}\left\{1+\frac{\{g(t)\}^{\prime}}{g(t)} \frac{k_{h+1}}{2}+O\left(k_{h+1}^{2}\right)\right\} \\
\Rightarrow & k_{h}^{3} g(t)\left\{1-\frac{\{g(t)\}^{\prime}}{g(t)} \frac{k_{h}}{2}+O\left(k_{h}^{2}\right)\right\} \\
= & k_{i}^{3} g(t)\left\{1+\frac{\{g(t)\}^{\prime}}{g(t)} \frac{k_{h+1}}{2}+O\left(k_{h+1}^{2}\right)\right\}
\end{aligned}
$$

The identity proposed by Singh and Sukhatme [12] and used by, inter alia, Gupt and Ahamed [29,30] and Gupt et al. [31] is as follows:

$$
\begin{gathered}
{\left[\int_{m}^{\mathrm{n}} \sqrt{f(t)} d t\right]^{\alpha}=k^{\alpha} f(\mathrm{~m})\left[1+\frac{k_{i}}{2} \frac{f(\mathrm{~m})}{f(\mathrm{~m})}+O\left(k^{2}\right)\right]} \\
=k^{\alpha-1} \int_{\mathrm{m}}^{\mathrm{n}} f(t) d t\left(1+O\left(k^{2}\right)\right)
\end{gathered}
$$

where $k=n-m$

Using the identity (20) in (19), we proceed as follows:

$$
\begin{gathered}
\Rightarrow k_{h}^{2} \int_{x_{h-1}}^{x_{h}} g(t) d t\left\{1+O\left(k_{h}^{2}\right)\right\} \\
=k_{h+1}^{2} \int_{x_{h}}^{x_{h+1}} g(t) d t\left\{1+O\left(k_{h+1}^{2}\right)\right\} .
\end{gathered}
$$

Since $h=1,2,3, \ldots$, ., $L$, the equality holds for all the strata, therefore, we get

$$
\begin{aligned}
k_{h}^{2} \int_{x_{h-1}}^{x_{h}} g(t) d t & =C_{1} \\
\Rightarrow \int_{x_{h-1}}^{x_{h}} \sqrt[3]{g(t)} d t & =C_{2}
\end{aligned}
$$

The AOSB corresponding to exact equations (14) are given by the two equivalent methods (21) and (22). The values of constants $C_{1}$ and $C_{2}$ can be approximately 
evaluated by $C_{1}=\frac{1}{L}(b-a)^{2} \int_{a}^{b} g(t) d t \quad$ and $\quad C_{2}=$ $\frac{1}{L} \int_{a}^{b} \sqrt[3]{g(t)} d t$ respectively, where we assume $b$ and $a$ are upper and lower bounds of points of stratification $x_{h}{ }^{\prime} s$, i.e., $a \leq x_{h} \leq b$.We can use (21) and (22) in finding AOSB, i.e., $x_{h}{ }^{\prime} s$ by fixing lower boundary $x_{h-1}$ every time.

Thus, the above analytical study has led to arrive at the following theorem.

Theorem 1: If the function $g(x)$ is bounded and possesses first two partial derivatives for all values of $x$ in $(a, b)$, for a given number of strata, taking equal intervals on the cumulative of $\sqrt[3]{g(x)}$ gives AOSB.

\subsection{Other Approximations Using Assumptions on Coefficient of Variation}

Again, we deduce some more methods of approximation from exact equations (14), these approximation methods are still implicit but easy to use. We proceed as follows:

Equations (14) can be rewritten as

$$
\begin{aligned}
& \left\{x_{h}-\mu_{h}(x)\right\}\left\{\frac{x_{h}}{\mu_{h}(x)}-1-c_{h x}^{2}\right\} \\
= & \left\{x_{h}-\mu_{h+1}(x)\right\}\left\{\frac{x_{h}}{\mu_{h+1}(x)}-1-c_{(h+1) x}^{2}\right\},
\end{aligned}
$$

where $c_{h x}^{2}$ and $c_{(h+1) x}^{2}$ are the square of coefficients of variation of $h^{\text {th }}$ and $(h+1)^{t h}$ strata.

If we consider square of coefficients of variation are approximately equal for every two successive strata, i.e., $c_{h x}^{2} \approx c_{(h+1) x}^{2}$ and approximately equal to arithmetic mean of square of coefficients of variation of the consecutive strata, then AOSB are given by

$$
x_{h}=\sqrt{\left(1+\bar{C}_{\left(h+\frac{1}{2}\right) x}^{2}\right) \mu_{h}(x) \mu_{h+1}(x)},
$$

where $\bar{C}_{\left(h+\frac{1}{2}\right) x}^{2}=\frac{c_{h x+}^{2} c_{(h+1) x}^{2}}{2}$

If we consider the square of coefficients of variation for every two successive strata are approximately equal to geometric mean of the square of coefficients of variation the two consecutive strata, AOSB are given by

$$
x_{h}=\sqrt{\left(1+\tilde{C}_{\left(h+\frac{1}{2}\right) x}\right) \mu_{h}(x) \mu_{h+1}(x)}
$$

where $\tilde{C}_{\left(h+\frac{1}{2}\right) x}=c_{h x} c_{(h+1) x}$

If we consider square of coefficients of variation are negligibly small relative to unity, AOSB are given by

$$
x_{h}=\sqrt{\mu_{h}(x) \mu_{h+1}(x)}
$$

Thus, we have obtained (24), (25) and (26) as approximations to equations (14) to give AOSB.

\section{Empirical Illustration}

The proposed exact equations (14) and methods of approximation (22), (24), (25) and (26) are illustrated in stratifying population of two districts, Lunglei and Serchhip districts, of Mizoram, a state of India, in which villages are taken as elements of cluster. The data of villages is taken from Village Profile \& Development Indicators [34]. There are 193 villages in the two districts. We take number of households of a village as the study variable $y$ and population of village as the auxiliary variable $x$. The correlation between the study variable $y$ and stratification variable $x$ is sufficiently high, i.e., 0.9604 . The data is shown in appendix I.

Mizoram is a hilly state of India, $88.93 \%$ of the total geographical area is covered by hilly forests; the villages and towns are spread over the hilly terrain of the state. There are rolling hills, tiny valleys, rivers and lakes in the state. Villages are connected by mostly minor and a few major hilly roads. In many cases, the geographical distance between any two villages may be short but they are separated by rivers, lakes, streams, and swamps in the thick rainforest. Therefore, the road transport connecting the two villages may be extremely long requiring lots of energy and time to travel from one to the other. Considering physical feature of the land and pattern of distribution of villages, stratified cluster sampling may be an appropriate sampling design in survey planning. Therefore, we use Google Earth pro and Geographic Information System to locate the villages, rivers, minor roads, major roads, hill ranges and altitudes while forming the clusters. The clusters are formed not only by combining the villages connected by the shortest roads but also taking in account other constraints like variation in altitude and separation by rivers, lakes and thick forest cover. The formation of clusters is shown in appendix II.

In the case of illustrating methods of approximation (21) and (22), since we have theoretically proven both the methods are equivalent, we conveniently use (22). While using (22), we require a Probability Density Function (PDF) that the auxiliary variable $x$ follows. For fitting a suitable distribution, we use the data of $x$ variable in which each value of the variable is divided by 1000 . We have two sets of data, one is when each cluster is made of two villages, i.e., cluster size, $M=2$ and the other is when each cluster is made of three villages, i.e., cluster size, $M=3$.

We try to find the most suitable PDF that the $x$ variable of the live data follows. The fitdistrplus package in R-software is used in fitting a number of known PDFs in data of $x$ variable of both the populations by using the methods - Maximum Likelihood Estimation (MLE), Moment Matching Estimation (MME) and Quantile Matching Estimation (QME) one after another.

Of all the various PDFs we have tried to fit to the data, Gamma Probability Density Function (GPDF) is found to 
be fitting best to the data of both populations; the decision of best fitting is made by taking into consideration simultaneously the values of LL (log likelihood), AIC (Akaike Information Criteria), BIC (Bayesian Information Criteria) and standard errors (s.e $e$ ) of parameters.

Thus, the PDF followed by the $x$ variable is as follows:

$$
f(x)=\frac{\beta^{\alpha}}{\Gamma(\alpha)} x^{\alpha-1} e^{-\beta x}
$$

where $\alpha>0, \beta>0, \forall x \in(0, \infty)$

The two populations are characterised as follows in fitting GPDF to them.

a. In the data for $M=2$, shape parameter $\alpha=$ 2.24436 , rate parameter $\beta=1.49746$, s. $e(\alpha)=$ 0.302965 , s. $e(\beta)=0.226425, L L=-120.354$, $A I C=244.7089, \quad B I C=249.8376$, which are estimated by MLE method.

b. In the data for $M=3$, shape parameter $\alpha=$ 3.29280 , rate parameter $\beta=1.464706$, s. $e(\alpha)=$ 0.551335 , s.e $(\beta)=0.266752, L L=-97.53638$, $A I C=199.0728, \quad B I C=203.3905$, which are estimated by MLE method.

We use the above PDF (27) in illustrating approximation method (22), along with the estimates of parameters, in stratifying both the populations. Numerical integration and differentiation methods are used in working out the approximation method in stratifying the populations.

We examine the performance of all the proposed methods of stratification in the stratified cluster sampling design in the two sampling frames. At first, we illustrate the methods in the population in which cluster is formed by the combination of two villages and secondly in the population in which cluster is formed by combination of three villages; the results are shown in Tables 1, 2, 3 and 4 . For population of clusters of size two, we present points of stratification due to all the proposed methods of stratification in Table 1 and the variances and relative efficiencies due to the methods in Table 2. Similarly, for population of clusters of size 3 , we present the said results in the same way in Tables 3 and 4. Each of the two populations is stratified into two, three, four, five, and six strata by using the all the proposed stratification methods and equal interval stratification. The efficiencies of the proposed methods are compared with that of equal interval stratification in both the populations for each considered number of strata, $L=2,3,4,5$ and 6 .

Table 1. Points of stratification in the population of clusters of size two, $M=2$

\begin{tabular}{|c|c|c|c|c|c|c|}
\hline \multirow[b]{2}{*}{$L$} & \multicolumn{6}{|c|}{ Points of stratification } \\
\hline & $\begin{array}{l}\text { Equal Interval } \\
\text { Stratification }\end{array}$ & $\begin{array}{c}\text { Stratification due } \\
\text { to Exact equations } \\
\text { (14) }\end{array}$ & $\begin{array}{l}\text { Stratification due } \\
\text { to approx. method } \\
\text { (22) }\end{array}$ & $\begin{array}{l}\text { Stratification due } \\
\text { to approx. method } \\
\text { (24) }\end{array}$ & $\begin{array}{l}\text { Stratification due } \\
\text { to approx. method } \\
(25)\end{array}$ & $\begin{array}{l}\text { Stratification due } \\
\text { to approx. method } \\
\text { (26) }\end{array}$ \\
\hline 2 & 2606 & 1948.76 & 1670.25 & 1956.62 & 1948.17 & 1576.24 \\
\hline 3 & $\begin{array}{l}1737.33 \\
3474.37\end{array}$ & $\begin{array}{l}1195.17 \\
2562.68\end{array}$ & $\begin{array}{l}1054.43 \\
2446.52\end{array}$ & $\begin{array}{l}1197.12 \\
2562.16\end{array}$ & $\begin{array}{l}1181.24 \\
2551.44\end{array}$ & $\begin{array}{l}1138.76 \\
2488.94\end{array}$ \\
\hline 4 & $\begin{array}{l}1303 \\
2606 \\
3909\end{array}$ & $\begin{array}{l}1141.11 \\
2170.56 \\
3714.61\end{array}$ & $\begin{array}{c}785.83 \\
1670.23 \\
2930.7\end{array}$ & $\begin{array}{l}1143.14 \\
2170.90 \\
3715.32\end{array}$ & $\begin{array}{l}1134.86 \\
2170.72 \\
3714.08\end{array}$ & $\begin{array}{c}938.54 \\
1910.28 \\
3421.17\end{array}$ \\
\hline 5 & $\begin{array}{l}1042.40 \\
2084.80 \\
3127.20 \\
4169.60\end{array}$ & $\begin{array}{l}1037.59 \\
1867.38 \\
2871.18 \\
4083.96\end{array}$ & $\begin{array}{c}633.96 \\
1286.33 \\
2110.77 \\
3267.01\end{array}$ & $\begin{array}{c}1039.08 \\
1868.23 \\
2871.44 \\
4084\end{array}$ & $\begin{array}{l}1023.56 \\
1859.03 \\
2870.71 \\
4083.99\end{array}$ & $\begin{array}{c}665.25 \\
1212.51 \\
2063.53 \\
3513.50\end{array}$ \\
\hline 6 & $\begin{array}{c}868.67 \\
1737.33 \\
2606 \\
3474.67 \\
4343.33\end{array}$ & $\begin{array}{c}685.69 \\
1224.06 \\
1965.15 \\
2901.17 \\
4083.96\end{array}$ & $\begin{array}{c}535.91 \\
1054.43 \\
1670.23 \\
2446.52 \\
3516.02\end{array}$ & $\begin{array}{c}763.70 \\
1300.39 \\
2005.12 \\
2901.25 \\
4084\end{array}$ & $\begin{array}{c}680.49 \\
1224.04 \\
1964.47 \\
2901.16 \\
4083.99\end{array}$ & $\begin{array}{c}665.25 \\
1212.51 \\
1952.09 \\
2890.63 \\
4071.54\end{array}$ \\
\hline
\end{tabular}


Table 2. Variance and Relative Efficiencies in the population of clusters of size two, $M=2$

\begin{tabular}{|c|c|c|c|c|c|c|c|c|c|c|c|}
\hline & \multicolumn{10}{|c|}{ Variances and Relative Efficiencies (RE) } \\
\cline { 2 - 14 }$L$ & $\begin{array}{c}\text { Equal } \\
\text { Interval } \\
n V\left(\bar{y}_{s t}\right)\end{array}$ & $\begin{array}{c}\text { Exact } \\
\text { equations } \\
(14) \\
n V\left(\bar{y}_{s t}\right)\end{array}$ & $\mathrm{RE}$ & $\begin{array}{c}\text { Approx. } \\
\text { method } \\
(22) \\
n V\left(\bar{y}_{s t}\right)\end{array}$ & $\mathrm{RE}$ & $\begin{array}{c}\text { Approx. } \\
\text { method } \\
(24) \\
n V\left(\bar{y}_{s t}\right)\end{array}$ & $\mathrm{RE}$ & $\begin{array}{c}\text { Approx. } \\
\text { method } \\
(25) \\
n V\left(\bar{y}_{s t}\right)\end{array}$ & $\begin{array}{c}\text { Approx. } \\
\text { method } \\
(26) \\
n V\left(\bar{y}_{s t}\right)\end{array}$ & $\begin{array}{c}\mathrm{RE} \\
\mathrm{RE}\end{array}$ \\
\hline 2 & 3837.94 & 3481.67 & 110.23 & 3769.89 & 101.78 & 3481.67 & 110.23 & 3481.67 & 110.23 & 3777.08 & 101.61 \\
\hline 3 & 2657.10 & 1747.45 & 152.06 & 1401.19 & 189.63 & 1747.45 & 152.06 & 1673.32 & 158.79 & 1542.09 & 172.31 \\
\hline 4 & 1929.32 & 1303.18 & 148.05 & 1389.96 & 138.80 & 1303.18 & 148.05 & 1303.18 & 148.05 & 1327.32 & 145.35 \\
\hline 5 & 1177.71 & 1110.60 & 106.04 & 997.14 & 119.75 & 1135.11 & 103.75 & 1157.05 & 101.79 & 917.41 & 128.37 \\
\hline 6 & 1198.35 & 904.22 & 132.53 & 693.87 & 179.28 & 1030.96 & 116.24 & 908.45 & 131.91 & 908.45 & 131.91 \\
\hline
\end{tabular}

Table 3. Points of stratification in the population of clusters of size three, $M=3$

\begin{tabular}{|c|c|c|c|c|c|c|}
\hline \multirow{2}{*}{$L$} & \multicolumn{6}{|c|}{ Points of stratification } \\
\cline { 2 - 7 } & $\begin{array}{c}\text { Equal Interval } \\
\text { Stratification }\end{array}$ & $\begin{array}{c}\text { Stratification due } \\
\text { to Exact equations } \\
(14)\end{array}$ & $\begin{array}{c}\text { Stratification due } \\
\text { to approx. method } \\
(22)\end{array}$ & $\begin{array}{c}\text { Stratification due } \\
\text { to approx. method } \\
(24)\end{array}$ & $\begin{array}{c}\text { Stratification due } \\
\text { to approx. method } \\
(25)\end{array}$ & $\begin{array}{c}\text { Stratification due } \\
\text { to approx. method } \\
(26)\end{array}$ \\
\hline 2 & 2760.5 & 2252.81 & 2267.28 & 2250.97 & 2250.16 & 2158.41 \\
\hline \multirow{3}{*}{3} & 1840.33 & 1882.76 & 1630.44 & 1884.89 & 1881.83 & 1843.76 \\
& 3680.67 & 3739.34 & 3054.09 & 3739.45 & 3739.44 & 3689.25 \\
\hline & 1380.25 & 1281.16 & 1344.91 & 1281.67 & 1279.91 & 1264.84 \\
& 2760.50 & 2206.93 & 2267.28 & 2206.61 & 2206.42 & 2187.85 \\
& 4140.75 & 4033.18 & 3543.94 & 4034.38 & 4032.78 & 4004.84 \\
\hline 5 & 1104.2 & 1242.71 & 1180.22 & 1243.07 & 1242.34 & 1227.82 \\
& 2208.4 & 2125.28 & 1872.54 & 2125.77 & 2125.17 & 2078.20 \\
& 3312.6 & 3277.32 & 2714.75 & 3277.28 & 3277.25 & 3120.91 \\
& 4416.8 & 4614.26 & 3886.22 & 4614.92 & 4612.71 & 4472.03 \\
\hline \multirow{4}{*}{6} & 920.17 & 1190.62 & 1072.32 & 1191.09 & 1189.21 & 1179.09 \\
& 1840.33 & 1854.31 & 1630.44 & 1854.06 & 1853.64 & 1806.41 \\
& 2760.5 & 2650.97 & 2267.28 & 2651.25 & 2649.21 & 2562.61 \\
\end{tabular}

Table 4. Variance and Relative Efficiencies in the population of clusters of size three, $M=3$

\begin{tabular}{|c|c|c|c|c|c|c|c|c|c|c|c|}
\hline \multirow[b]{2}{*}{$L$} & \multicolumn{11}{|c|}{ Variances and Relative Efficiencies (RE) } \\
\hline & $\begin{array}{c}\text { Equal } \\
\text { Interval } \\
n V\left(\bar{y}_{s t}\right)\end{array}$ & $\begin{array}{c}\text { Exact } \\
\text { equations } \\
(14) \\
n V\left(\bar{y}_{s t}\right)\end{array}$ & RE & $\begin{array}{c}\text { Approx. } \\
\text { method } \\
(22) \\
n V\left(\bar{y}_{s t}\right) \\
\end{array}$ & RE & $\begin{array}{c}\text { Approx. } \\
\text { method } \\
(24) \\
n V\left(\bar{y}_{s t}\right)\end{array}$ & RE & $\begin{array}{c}\text { Approx. } \\
\text { method } \\
(25) \\
n V\left(\bar{y}_{s t}\right) \\
\end{array}$ & RE & $\begin{array}{c}\text { Approx. } \\
\text { method } \\
(26) \\
n V\left(\bar{y}_{s t}\right)\end{array}$ & RE \\
\hline 2 & 2759.67 & 2097.53 & 117.27 & 2097.52 & 117.26 & 2097.53 & 117.27 & 2097.53 & 117.27 & 2097.53 & 117.27 \\
\hline 3 & 1025.14 & 1025.14 & 100 & 1078.06 & 95.09 & 1025.14 & 100 & 1025.14 & 100 & 1025.14 & 100 \\
\hline 4 & 1081.06 & 923.48 & 117.06 & 529.32 & 204.23 & 923.48 & 117.06 & 923.48 & 117.06 & 923.48 & 117.06 \\
\hline 5 & 675.81 & 580.56 & 116.41 & 555.01 & 121.76 & 580.56 & 116.41 & 580.56 & 116.41 & 633.51 & 106.68 \\
\hline 6 & 678.61 & 512.77 & 132.34 & 554.45 & 122.39 & 533.59 & 127.18 & 533.59 & 127.18 & 523.16 & 129.71 \\
\hline
\end{tabular}

It is seen that in the population of clusters of size two, the exact equations (14) perform with higher efficiencies at $L=2,5$ and much higher efficiencies at $L=3,4$ and 6 than that of equal interval stratification. In the same way, approximation methods (22), (24), (25) and (26) too perform when compared with equal interval stratification. Approximation methods (22) and (26) are found to be relatively better in overall performances than all the other four proposed methods of stratification.

In the population of clusters of size three, the exact equations (14), approximation methods (22), (24), (25) and (26) perform with considerably higher efficiencies than that of equal interval stratification at all the considered number of strata except when $L=3$ at which all the proposed methods of stratification other than (22) perform with same efficiency with equal interval stratification; method (22) performs with slightly lower efficiency than that of equal interval stratification at $L=3$. However, in all other number of strata, method (22) performs with strikingly high efficiencies; whereas all 
other proposed methods of stratification are performing with more or less same efficiency with that of method (22).

But, although the proposed methods of stratification perform well in both the populations, it is found that the methods perform relatively better in the population of clusters of size two than in the population of clusters of size three.

\section{Conclusions}

It is seen in stratified cluster sampling with clusters of equal size, the proposed methods of stratification are performing excellently. The inevitability of the use of cluster sampling due to the nature of spatial relationship between elements of a population or unavailability of proper sampling frame and strategy for ensuring the precision of estimator of population parameter are simultaneously addressed in stratified cluster sampling design presented in this paper. The exact equations (14) and approximation methods (24), (25) and (26) are all performing with more or less same efficiencies, rather interestingly, the approximation method (26), i.e., AOSB are given by the geometric mean of means of consecutive strata, is found to be performing slightly better than other three proposed methods of stratification- (14), (24) and (25). The approximation method (22) which is in the form definite integral of a defined function according to the population used performs best in the overall. Although the methods of approximation (24), (25) and (26) are implicit, they are easy to use. Therefore, all these proposed methods of stratification may be useful in the practical application of survey planning for socio-economic survey.

\section{Acknowledgements}

We, the authors of the article, express our sincere gratitude to the anonymous reviewer for the valuable suggestions provided to us during review.

\section{Appendix I}

Village wise population and number of households, Lunglei and Serchhip districts, Mizoram

\begin{tabular}{|c|c|c|c|c|c|c|c|}
\hline $\begin{array}{l}\text { SI. } \\
\text { No. }\end{array}$ & Name of village & Population & $\begin{array}{c}\text { No. of } \\
\text { household }\end{array}$ & Sl. No. & Name of village & Population & $\begin{array}{c}\text { No. of } \\
\text { household }\end{array}$ \\
\hline 1 & Thinglian & 504 & 82 & 62 & Sertlangpui & 560 & 110 \\
\hline 2 & Thentlang & 780 & 147 & 63 & Sesawm & 428 & 89 \\
\hline 3 & Sialhau & 600 & 109 & 64 & Thenhlum & 1266 & 250 \\
\hline 4 & Rullam & 650 & 112 & 65 & Terabonia & 525 & 104 \\
\hline 5 & Khumtung & 1340 & 254 & 66 & Tleu & 107 & 23 \\
\hline 6 & Khawbel & 757 & 131 & 67 & Tuikawi & 949 & 217 \\
\hline 7 & Lungpho & 1005 & 182 & 68 & Belthei & 631 & 105 \\
\hline 8 & Mualpui Chhingchhip & 1750 & 350 & 69 & Belpei & 1186 & 262 \\
\hline 9 & Vanchengte & 126 & 27 & 70 & Balukiasury & 193 & 37 \\
\hline 10 & Vanchengpui & 1000 & 170 & 71 & Balungsury & 356 & 79 \\
\hline 11 & Keitum & 2150 & 435 & 72 & Bindiasora & 490 & 115 \\
\hline 12 & Neihloh & 380 & 72 & 73 & Borsegojasora & 305 & 72 \\
\hline 13 & Ngentiang & 676 & 130 & 74 & Bomasury & 430 & 86 \\
\hline 14 & Hmunzawl & 538 & 110 & 75 & Chhumkhum & 212 & 53 \\
\hline 15 & Hmuntha & 1028 & 160 & 76 & Chhuahthum & 291 & 51 \\
\hline 16 & Hmawngkawn & 165 & 40 & 77 & Chawngte L & 1053 & 254 \\
\hline 17 & Hualtu & 1140 & 208 & 78 & Chawilung North & 369 & 65 \\
\hline 18 & Hriangtlang & 640 & 120 & 79 & Diblibagh & 1860 & 382 \\
\hline 19 & Bungtlang & 2263 & 435 & 80 & Gulsil & 227 & 54 \\
\hline 20 & Baktawng & 2050 & 336 & 81 & Hmunthar & 186 & 39 \\
\hline 21 & Buangpui & 485 & 105 & 82 & Kalapani & 556 & 107 \\
\hline
\end{tabular}




\begin{tabular}{|c|c|c|c|c|c|c|c|}
\hline 22 & Chhuanthar Tlangnuam & 2420 & 280 & 83 & Kauchhuah & 639 & 146 \\
\hline 23 & Chhingchhip & 2092 & 750 & 84 & Khawmawi & 1665 & 297 \\
\hline 24 & Sialsir & 344 & 57 & 85 & Khojoysuri & 410 & 82 \\
\hline 25 & Sailulak & 964 & 192 & 86 & Letisury & 386 & 58 \\
\hline 26 & Lungchhuan & 780 & 145 & 87 & Lalnutui & 304 & 64 \\
\hline 27 & Khawlailung & 2672 & 562 & 88 & Lamthai I & 354 & 80 \\
\hline 28 & Piler & 505 & 100 & 89 & Lamthai II & 763 & 168 \\
\hline 29 & Leng & 839 & 180 & 90 & Lamthai III & 281 & 51 \\
\hline 30 & Lungkawlh & 900 & 175 & 91 & Lungsen I & 1255 & 251 \\
\hline 31 & Mualcheng & 1510 & 300 & 92 & Lungsen II & 1716 & 322 \\
\hline 32 & Tuichang & 27 & 8 & 93 & Muriskata & 267 & 55 \\
\hline 33 & Bawktlang & 350 & 74 & 94 & Mautlang & 263 & 56 \\
\hline 34 & Chekawn & 350 & 54 & 95 & Nunsury II & 680 & 136 \\
\hline 35 & East Lungdar & 3700 & 735 & 96 & Ngiautlang & 204 & 44 \\
\hline 36 & Bandisora & 765 & 137 & 97 & New Balukiasury & 378 & 67 \\
\hline 37 & Bunghmun & 1232 & 230 & 98 & New Khojoysury & 803 & 195 \\
\hline 38 & Bungtlang & 255 & 56 & 99 & New Vuakmual & 315 & 62 \\
\hline 39 & Changpui & 457 & 103 & 100 & New Lungrang & 750 & 270 \\
\hline 40 & Dampui & 36 & 12 & 101 & Nunsury I & 852 & 186 \\
\hline 41 & Dengsur & 616 & 127 & 102 & Old Khojoysury & 490 & 123 \\
\hline 42 & Devasora & 835 & 145 & 103 & Phairuangchhuah & 244 & 48 \\
\hline 43 & Hmundo & 180 & 35 & 104 & Phairuangkai & 1200 & 308 \\
\hline 44 & Kawlhawk & 146 & 34 & 105 & Putlungasih & 1758 & 250 \\
\hline 45 & Lungchem & 401 & 85 & 106 & Rangte & 840 & 167 \\
\hline 46 & Lokhi Sury & 256 & 54 & 107 & Rolui & 543 & 95 \\
\hline 47 & Laisawral & 578 & 109 & 108 & Rotlang West & 750 & 154 \\
\hline 48 & Marpara South & 2691 & 571 & 109 & Rualalung & 380 & 82 \\
\hline 49 & Mauzam & 715 & 143 & 110 & S. Lungrang & 332 & 72 \\
\hline 50 & Malsury & 900 & 170 & 111 & Sailen & 132 & 30 \\
\hline 51 & New Sachan & 114 & 222 & 112 & Samuksury & 975 & 214 \\
\hline 52 & New Khawlek & 164 & 33 & 113 & Sedailui & 220 & 68 \\
\hline 53 & Puankhai & 1182 & 229 & 114 & Silkur & 345 & 73 \\
\hline 54 & Phainuam & 218 & 44 & 115 & Sihphirtlang & 126 & 28 \\
\hline 55 & South Khawlek & 140 & 30 & 116 & Sugorbasora & 537 & 111 \\
\hline 56 & Sumasumi & 487 & 103 & 117 & Tipperagath I & 1171 & 202 \\
\hline 57 & Salmur & 272 & 55 & 118 & Tipperaghat II & 636 & 122 \\
\hline 58 & Saisen & 255 & 55 & 119 & Tipperaghat III & 633 & 118 \\
\hline 59 & Sachan & 600 & 112 & 120 & Thanzamasora & 385 & 75 \\
\hline 60 & S. Lungdai & 280 & 53 & 121 & Thekaduar & 347 & 75 \\
\hline 61 & Serte & 446 & 89 & 122 & Tuichawngchhuah & 221 & 49 \\
\hline
\end{tabular}


Continued

\begin{tabular}{|c|c|c|c|c|c|c|c|}
\hline Sl. No. & Name of village & Population & $\begin{array}{c}\begin{array}{c}\text { No. of } \\
\text { household }\end{array} \\
\end{array}$ & SI. No. & Name of village & Population & $\begin{array}{c}\text { No. of } \\
\text { household }\end{array}$ \\
\hline 123 & Tuichawng & 3419 & 583 & 159 & Thualthu & 661 & 152 \\
\hline 124 & Tuisenchhuah & 330 & 85 & 160 & Thuampui & 467 & 115 \\
\hline 125 & Tuisen Bolia & 793 & 153 & 161 & Thingfal & 1789 & 323 \\
\hline 126 & Undermanik & 777 & 106 & 162 & Thangte & 170 & 38 \\
\hline 127 & Ugudasury & 491 & 109 & 163 & Thehlep & 28 & 8 \\
\hline 128 & Vuakmual & 6 & 1 & 164 & Tawipui South & 1388 & 216 \\
\hline 129 & Vairawkai & 185 & 35 & 165 & Thaizawl & 400 & 83 \\
\hline 130 & Zehtet & 596 & 118 & 166 & Thangpui & 154 & 32 \\
\hline 131 & Zawlpui & 1766 & 352 & 167 & Tawipui North I & 712 & 167 \\
\hline 132 & Zohmun & 487 & 96 & 168 & Tawipui North II & 874 & 201 \\
\hline 133 & Serhuan & 597 & 135 & 169 & Vaisam & 357 & 81 \\
\hline 134 & Buknuam & 393 & 81 & 170 & Vanhne & 820 & 201 \\
\hline 135 & Buarpui & 1450 & 360 & 171 & Aithur & 220 & 36 \\
\hline 136 & Bualpui V & 720 & 112 & 172 & Bualpui $\mathrm{H}$ & 1114 & 205 \\
\hline 137 & Bualte & 446 & 96 & 173 & Cherhlun & 2492 & 486 \\
\hline 138 & Chengpui & 180 & 38 & 174 & Denlung & 130 & 24 \\
\hline 139 & Chithar & 220 & 52 & 175 & Darzo & 1590 & 310 \\
\hline 140 & Chhipphir & 1411 & 287 & 176 & Khawhri & 430 & 94 \\
\hline 141 & Dawn & 430 & 72 & 177 & Kutkawk & 5 & 3 \\
\hline 142 & Haulawng & 2245 & 527 & 178 & Lungpuitlang & 204 & 50 \\
\hline 143 & Hlumte & 210 & 37 & 179 & Leite & 785 & 170 \\
\hline 144 & Hmuntlang & 122 & 24 & 180 & Maudarh & 74 & 18 \\
\hline 145 & Kanghmun South & 537 & 135 & 181 & Muallianpui & 1214 & 219 \\
\hline 146 & Mamte & 852 & 127 & 182 & New Ngharchhip & 757 & 103 \\
\hline 147 & Mausen & 300 & 70 & 183 & Old Ngharchhip & 168 & 65 \\
\hline 148 & Mualcheng South & 960 & 167 & 184 & Pangzawl & 3170 & 503 \\
\hline 149 & Mualthuam North & 1519 & 330 & 185 & Rawpui & 1050 & 174 \\
\hline 150 & Lungmawi & 272 & 52 & 186 & Rotlang E & 732 & 161 \\
\hline 151 & Pachang & 39 & 13 & 187 & South Vanlaiphai & 1991 & 390 \\
\hline 152 & Phaileng South & 330 & 63 & 188 & S. Lungleng & 157 & 31 \\
\hline 153 & Ramlaitui & 657 & 158 & 189 & S. Chawngtui & 696 & 140 \\
\hline 154 & Ralvawng & 520 & 76 & 190 & Tuipui D & 945 & 202 \\
\hline 155 & Runtung & 211 & 34 & 191 & Thiltlang & 1364 & 249 \\
\hline 156 & Sairep & 264 & 52 & 192 & Thingsai & 2536 & 503 \\
\hline 157 & Sekhum & 384 & 85 & 193 & Tarpho & 450 & 95 \\
\hline 158 & Thlengang & 240 & 43 & & & & \\
\hline
\end{tabular}




\section{Appendix II}

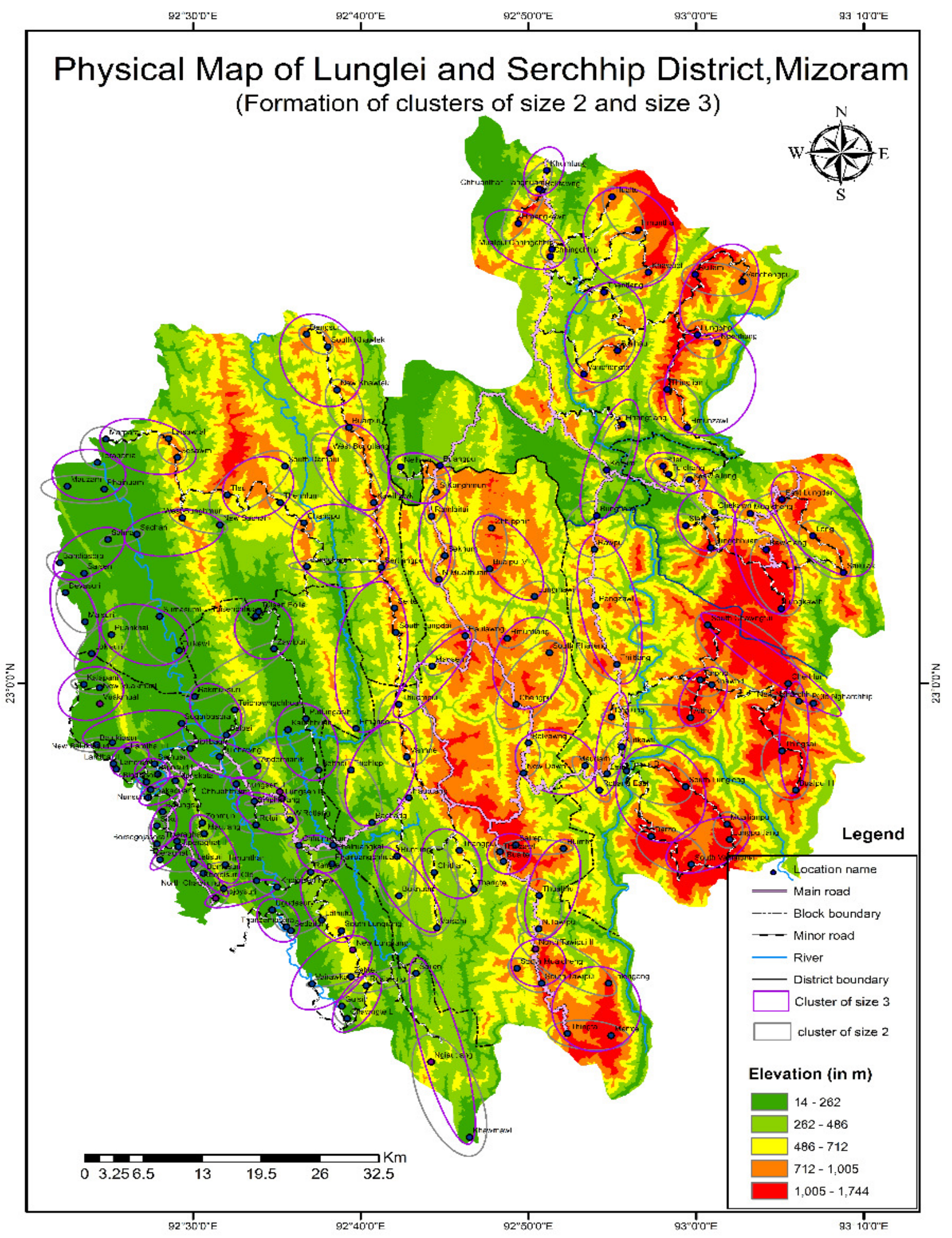




\section{REFERENCES}

[1] T. Dalenius. The problem of optimum stratificationI.Skandinavisk Aktuaritidskrift, Vol. 33,203-213, 1950.

[2] A.A. Tschuprow. On mathematical expectation of the moments of frequency distributions in the case of correlated observations. Metron, Vol.2, 461-493, 1923.

[3] J. Neyman. On two different aspects of the representative method: the method of stratified sampling and the method of purposive selection.Journal of the Royal Statistical Society, Vol. 97, No.4,558-625, 1934.

[4] T. Dalenius, M. Gurney. The problem of optimum stratification-II. Skandinavisk Aktuaritidskrift, Vol. 34, 133-148, 1951.

[5] P.C. Mahalanobis. Some aspects of the design of sample surveys, Sankhya, Vol. 12, 1-7, 1952.

[6] M.H. Hansen, W.N. Hurwitz, W.G. Madow. Sample survey methods and theory, Vol. I and II, New York: John Wiley and Sons, Inc, 1953.

[7] T. Dalenius, J.L. Hodges. The Choice of stratification points, Skandinavisk Aktuaritidskrift, Vol. 34, 198-203, 1957.

[8] T. Dalenius, J.L. Hodges. Minimum variance stratification. Jour. Amer. Stat. Assoc., Vol. 54, 88-101, 1959.

[9] G. Ekman. An approximation useful in univariate stratification. The Annals of Mathematical Statistics, Vol. 30, 219-229, 1959.

[10] T. Dalenius. Sampling in Sweden. Contributions to the methods and theories of sample survey practice. Almqvist and Wicksell, Stockholm, 1957.

[11] Y. Taga. On optimum stratification for the objective variable based on concomittant variable.Annals of the Institute of Statistical Mathematics, Vol. 19,101-130, 1967.

[12] R. Singh, B.V. Sukhatme. Optimum stratification. Annals of the Institute of Statistical Mathematics, Vol. 21, 515-528, 1969.

[13] R. Singh. Approximately optimum stratification on the auxiliary variable. Journal of the American Statistical Association, Vol. 66, 829-833, 1971.

[14] R. Singh. An alternate method of stratification on the auxiliary variable. Sankhya, Vol. 37, 100-108, 1975.

[15] R. Singh. On optimum stratification for proportional allocation. Sankhya, Vol. 37, Pt. I, 109-115, 1975.

[16] R. Singh. A note on optimum stratification in sampling with varying probabilities. Australian Journal of Statistics, Vol. 27, No. 1, 12-21, 1975.

[17] R. Singh, D. Prakash. Optimum stratification for equal allocation. Annals of the Institute of Statistical Mathematics, Vol. 27, 273-280, 1975.

[18] S.S. Yadava, R. Singh. Optimum stratification for allocation proportional to strata totals for simple random sampling scheme. Communications in Statistics: Theory and Methods, Vol. 13, No. 22, 2793-2806, 1984

[19] S.P. Gosh. Optimum stratification with two characters, Ann. Maths. Statist., Vol. 34, 866-872, 1963.

[20] P.C. Gupta, G.R. Seth. On stratification in sampling investigation involving more than one character. J. Ind. Soc. Agril. Statist., Vol. 31, No. 2, 1-15, 1979.

[21] S.E.H. Rizvi, J.P. Gupta, R. Singh. Approximately optimum stratification for two study variables using auxiliary information, J. Ind. Soc. Agril. Statist., Vol. 53, No. 3, $287-298,2000$

[22] S.E.H. Rizvi, J.P. Gupta, M. Bhargava. Effect of optimum stratification on sampling with varying probabilities under proportional allocation. Statistica, Vol. 64, No. 4, 721-733, 2004.

[23] F. Danish, S.E.H. Rizvi. Optimum stratification in bivariate auxiliary variables under Neyman allocation. Journal of Modern Applied Statistical Methods, Vol. 17, No. 1, 1-24, 2018. doi: $10.22237 / \mathrm{jmasm} / 1529418671$.

[24] T.V. Hanurav. Optimum Sampling Strategies and Some Related Problems, unpublished Ph.D thesis submitted to the Indian Statistical Institute, 1965.

[25] T.J. Rao. On the allocation of sample size in stratified sampling. Ann. Inst. Stat. Math, Vol. 20, 159-166, 1968.

[26] B.K. Gupt, T.J. Rao.Stratified PPS sampling and allocation of sample size. Jour. Ind. Soc. Ag. Statistics, Vol. 50, No.2, 199-208, 1997.

[27] B.K. Gupt. Sample size allocation for stratified sampling under a correlated superpopulation model. METRONInternational Journal of Statistics, Vol. LXI, No. 1, 35-52, 2003.

[28] B.K. Gupt. Allocation of Sample Size in Stratified Sampling Under Superpopulation Models. Saarbrucken, Deutschland/Germany: LAP LAMBERT Academic Publishing AV Akademikerverlag GmbH \& Co.KG, 2012.

[29] B.K. Gupt, M.I. Ahamed. Optimum stratification for a generalized auxiliary variable proportional allocation under a superpopulation model. Communications in Statistics-Theory and Methods, Published online: 25 July 2020. https://doi.org/10.1080/03610926.2020.1793203

[30] B.K. Gupt, M.I. Ahamed. Construction of strata for a model-based allocation under a superpopulation model, Journal of Statistical Theory and Applications, Vol. 20, No. 1, 46-60, 2021.

[31] B.K. Gupt, M.I. Ahamed, M. Phukon. Optimum stratification for an auxiliary variable optimum allocation under a superpopulation model, Advances and Applications in Statistics, Vol. 67, No.1, 1-20, 2021.

[32] S. Mehta, V.L. Mandowara. An optimum stratification for stratified cluster sampling design when clusters are of varying sizes. International Journal of Scientific \& Technology Research, Vol. 1, No. 9, 74-79, 2012. 
[33] G. Ekman. Approximate expressions for the conditional mean and variance over small intervals of a continuous distribution. The Annals of Mathematical Statistics, Vol. 30, No. 4, pp. 1131-1134, 1959b.
[34] Village profile \& Development Indicators 2017- 2018 Mizoram state' published by Directorate of Economics and Statistics Government of Mizoram, Mizoram: Aizawl. https://des.mizoram.gov.in/page/village-profile-2017-2018 -mizoram-state 